\title{
Hyperglycemia enhances the invasive and migratory activity of pancreatic cancer cells via hydrogen peroxide
}

\author{
WEI LI, QINGYONG MA, JUNHUI LI, KUN GUO, HAN LIU, LIANG HAN and GUODONG MA \\ Department of Hepatobiliary and Pancreas Surgery, First Affiliated Hospital, \\ Xi'an Jiaotong University, 277 West Yanta Road, Xi'an 710061, P.R. China
}

Received November 1, 2010; Accepted December 3, 2010

DOI: $10.3892 /$ or.2011.1150

\begin{abstract}
Diabetes mellitus and pancreatic cancer are intimately related. Hyperglycemia, a chronic abnomality in diabetes, has been proved to be an independent predictor of mortality from cancer of the pancreas. However, little is known regarding the effect of hyperglycemia on pancreatic cancer cells. The aim of the present study was to evaluate whether increases in glucose concentration modulate the invasive and migratory potential of cancer cells, contributing to their enhanced metastatic behavior. Human pancreatic cancer cells BxPC-3 and Panc-1 were cultured in $5.5,25$ or $55 \mathrm{mM}$ glucose for 12,24 or $48 \mathrm{~h}$ in the absence or presence of superoxide dismutase and catalase. The intracellular reactive oxygen species were determined using 2,7-dichlorodihydrofluorecein diacetate. Wound healing assay and transwell invasion assay were used to detect the migratory and invasive potential of cancer cells. The invasion-related factor, urokinase plasminogen activator, was measured by RT-PCR and Western blot analysis. The production of reactive oxygen species was increased by glucose in a concentrationdependent manner. High glucose significantly enhanced the cell migration and invasion potential. Meanwhile, the expression of urokinase plasminogen activator was also increased. Superoxide dismutase-dependent production of hydrogen peroxide led to increased cell invasive and migratory ability and the expression of urokinase plasminogen activator. These increases were reversed by the hydrogen peroxidedetoxifying enzyme catalase. These results suggest that the association between hyperglycemia and poor prognosis in pancreatic cancer can be attributed to the alterations of the migratory and invasive ability of the cells through the production of hydrogen peroxide.
\end{abstract}

\section{Introduction}

The poor prognosis of patients with pancreatic cancer (PC) is attributed to the local invasion and early metastasis of tumor

Correspondence to: Dr Qingyong Ma, Department of Hepatobiliary and Pancreas Surgery, First Affiliated Hospital, Xi'an Jiaotong University, 277 West Yanta Road, Xi'an 710061, P.R. China

E-mail: qyma56@mail.xjtu.edu.cn

Key words: pancreatic cancer, hyperglycemia, hydrogen peroxide, invasion, migration cells. Previous studies have shown that more than $80 \%$ of PC patients have locally advanced or metastatic disease and thus are not amenable for resection at the time of diagnosis $(1,2)$. Diabetes has been postulated to be both a risk factor and a consequence of pancreatic cancer. Nearly $80 \%$ of PC patients are either diabetic or hyperglycemic. Recently, diabetes or even hyperglycemia has been demonstrated to be an independent predictor of mortality from cancer of the pancreas $(3,4)$.

Hyperglycemia can lead to oxidative stress that is caused by an imbalance in reactive oxygen species (ROS) antioxidants. ROS include a number of chemically reactive molecules derived from oxygen, such as superoxide anion, hydrogen peroxide, hydroxyl radical and nitric oxide. High glucose levels can stimulate production of hydrogen peroxide through several pathways $(5,6)$. Additionally, hyperglycemia also increase formation of superoxide anions through the mitochondrial electron-transport chain (7) which can be further converted to hydrogen peroxide by a spontaneous reaction. Intrinsic antioxidant enzymes are vital to the regulation of oxidative stress within cells. However, hyperglycemia can attenuate antioxidant enzymes activity and in turn create a state of oxidative stress $(8,9)$.

The most primary cellular antioxidant enzymes are superoxide dismutase (SOD) and catalase (CAT). Although they are sometimes classified together, they should be separately considered because their reactions are completely different. SOD catalyzes the conversion of superoxide anion to hydrogen peroxide which then be removed by catalase (CAT) (10). Some in vitro studies have shown that a number of cancer cell lines, including the metastatic pancreatic cancer cell line Capan-1, contain elevated levels of mitochondrial manganese-containing superoxide dismutase and decreased levels of CAT, and that this change in steady-state levels of hydrogen peroxide correlates with increased metastasis, proliferation, and resistance to apoptosis $(11,12)$. In vivo studies also proved that CAT greatly reduces the number of metastatic colonies in liver and lung $(13,14)$. An essential step in metastasis is the degradation of the extracellular matrix and basement membrane by proteolytic enzymes. Urokinase plasminogen activator (uPA) is one of the major contributors of stromal degradation and has been shown to mediate cell migration and invasion $(15,16)$. It has been proved that ROS and the expression of uPA are intimately related $(17,18)$.

Since most patients with PC suffer with diabetes or hyperglycemia, and high glucose can cause the production of 
ROS which in turn may increase the invasiveness of cancer cells. In this study therefore, we tested the hypothesis that hyperglycemia can increase the invasive and migratory properties of PC cell lines. We also examined the role of SOD and CAT in cell invasion and migration using an in vitro model in order to demonstrate that this increase was attibuted to the production of hydrogen peroxide. Results from this study suggest that the hyperglycemia may worsen the prognosis of PC by enhancing their migratory and invasive ability through the production of hydrogen peroxide.

\section{Materials and methods}

Preparation of chemicals. Dulbecco's modified Eagle's medium (DMEM) and fetal bovine serum (FBS) were purchased from Gibco (Grand Island, NY, USA). TRIzol was obtained from Invitrogen (Carlsbad, CA, USA). SOD and CAT were purchased from Sigma-Aldrich (St. Louis, MO, USA). The reactive oxygen species assay kit was obtained from Beyotime (Jinan, China) The RT-PCR kit was purchased from Fermentas Life Sciences (Vilnius, Lithuania). Millicell transwells for the invasion assays were obtained from Millipore (Billerica, MA, USA). A primary antibody against uPAR was purchased from Santa Cruz Biotechnology (Santa Cruz, USA). Antibody against uPA was purchased from Abcam (Cambridge, MA, USA). Nitrocellulose membranes were purchased from Millipore (Bedford, MA, USA).The BCA assay kit and the chemiluminescence kit were purchased from Pierce (Rockford, IL, USA).

Cell cultures and treatments. The human pancreatic cancer cell lines BxPC-3 and Panc-1 (obtained from the American Tissue Type Collection, USA) were maintained in DMEM supplemented with penicillin $(100 \mathrm{U} / \mathrm{ml})$, streptomycin $(100 \mu \mathrm{g} / \mathrm{ml})$ and $10 \% \mathrm{FBS}$ and were incubated in a $95 \%$ air/ $5 \% \mathrm{CO}_{2}$ humidified atmosphere at $37^{\circ} \mathrm{C}$. The cells were exposed to different glucose concentrations ranging from 5.5 to $55 \mathrm{mM}$ for 12,24 and $48 \mathrm{~h}$. SOD (400 U/ml) was used to convert superoxide anions into molecular oxygen and hydrogen peroxide, CAT $(400 \mathrm{U} / \mathrm{ml})$ was also added to the in vitro model in combination with SOD to decompose the hydrogen peroxide.

Measurement of intracellular hydrogen peroxide. The level of intracellular hydrogen peroxide was measured using the reactive oxygen species assay kit. In brief, cells were incubated with 2,7-dichlorodihydrofluorecein diacetate (DCFDA) for $30 \mathrm{~min}$, washed in phosphate-buffered saline (PBS) 3 times, and fluorescence intensity measured using a fluorometer (Becton-Dickinson, USA) with excitation at $488 \mathrm{~nm}$ and emission at $525 \mathrm{~nm}$.

Wound healing assay. Cells were grown to confluence and wounded by dragging a $1-\mu 1$ pipette tip through the monolayer. Cells were washed in PBS 3 times to remove cellular debris and then allowed to migrate for $24 \mathrm{~h}$. Images were taken at time 0 and $24 \mathrm{~h}$ post-wounding under a Nikon Diaphot TMD inverted microscope $(\mathrm{x} 10)$. The relative distance traveled by the leading edge from 0 to $24 \mathrm{~h}$ was assessed using Photoshop software $(n=5)$.
Matrigel invasion assay. An invasion assay was performed with a Millicell invasion chamber in 24-well plates (Millipore, Billerica, MA, USA). The $8-\mu \mathrm{m}$ pore inserts were coated with $25 \mu 1$ of Matrigel (Becton-Dickinson Labware, Bedford, MA, USA). The BxPC-3 and Panc-1 cells were seeded in the top chamber at a concentration of $2.5 \times 10^{5}$ and were cultured in different glucose concentrations with $1 \% \mathrm{FBS}$ in the absence or presence of SOD or SOD accompanied with CAT at concentrations of $400 \mathrm{U} / \mathrm{ml}$ each. Culture medium with $20 \%$ FBS was added at the bottom chamber to induce the cancer cell lines. The Matrigel invasion chamber was incubated for $24 \mathrm{~h}$ in a humidified tissue culture incubator. Noninvading cells were removed from the top of the Matrigel coated inserts with a cotton-tipped swab. Invading cells on the bottom surface of the filter were stained with Crystal Violet (Boster Biological Technology Ltd., Wuhan, China). Invasion ability was determined by counting the stained cells. Three random fields were captured at x20 magnification $(n=3)$.

Reverse transcription-polymerase chain reaction ( $R T-P C R)$ analysis. BXPC-3 and Panc-1 cells were cultured with glucose levels in the media from 5.5 to $55 \mathrm{mM}$ at culture times of 12 , 24 and $48 \mathrm{~h}$. Total RNA was isolated using TRIzol reagent according to the manufacturer's instructions. First-strand cDNA was synthesized from $2 \mu \mathrm{g}$ of total RNA using the RevertAid Kit. The primers were designed as follows: uPA: forward, 5'-CTTGAGGGAGCTTAGCCAAT-3' and reverse, 5'-TCACAGGTCATGCTGCAGAA-3' (323 bp). uPAR: forward, 5'-AACTCTGGCCGGGCTGTCAC-3' and reverse, 5'-TTCTTCAGGGCTGCGGCACT-3' (122 bp). ß-actin (used as a loading control): forward, 5'-ATCGTGCGTGACATTA AGGAGAAG-3' and reverse, 5'-AGGAAGGAAGGCTG GAAGAGTG-3' (179 bp). PCR were amplified under the following conditions: $94^{\circ} \mathrm{C}$ for $5 \mathrm{~min}, 30$ cycles of denaturation for $30 \mathrm{sec}$ at $94^{\circ} \mathrm{C}, 30 \mathrm{sec}$ of annealing at $59^{\circ} \mathrm{C}$, elongation at $72^{\circ} \mathrm{C}$ for $30 \mathrm{sec}$ and extension at $72^{\circ} \mathrm{C}$ for $5 \mathrm{~min}$. PCR products were run by electrophoresis on $1.5 \%$ agarose gel in 1X TAE buffer at $110 \mathrm{~V}$ for $30 \mathrm{~min}$ at room temperature. The resulting bands on the gel were photographed and analyzed using a gel-imaging analyzer. Levels of gene expression were expressed as the ratios of densities between PCR products and $\beta$-actin in the same sample.

Protein extraction and Western blotting. Total protein was extracted from cultured cells in Radio-ImmunoPrecipitation Assay (RIPA) lysis buffer on ice for $25 \mathrm{~min}$. Insoluble materials were removed by centrifugation at $4{ }^{\circ} \mathrm{C}$ with $15000 \mathrm{x} g$ for $15 \mathrm{~min}$. Subsequently, supernatants were collected and total protein concentrations were measured using the BCA assay kit. Clarified protein lysates (30-80 $\mu \mathrm{g})$ were electrophoretically resolved on a denaturing SDS polyacrylamide gel (10-12\%) and electrotransferred onto the nitrocellulose membranes. The membranes were initially blocked in $10 \%$ non-fat dry milk in Tris-buffered saline (TBS) for $2 \mathrm{~h}$ and then probed with specific primary antibodies to uPA, UPAR and $\beta$-actin (loading control). After co-incubation with the primary antibodies at $4{ }^{\circ} \mathrm{C}$ overnight, membranes were blotted with the secondary antibody for $2 \mathrm{~h}$ at $37^{\circ} \mathrm{C}$. The results were visualized using the ECL Western blotting substrate and photographed by GeneBox (SynGene). 

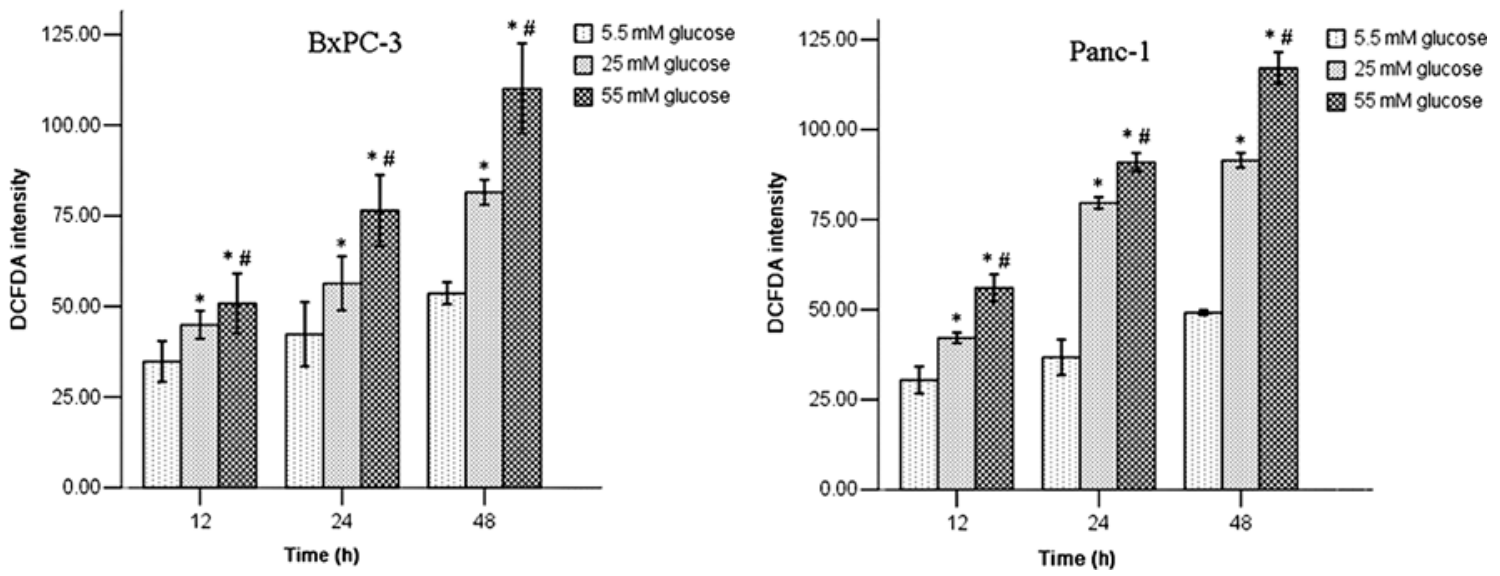

Figure 1. Hyperglycemia promotes the formation of hydrogen peroxide. Flow cytometry analysis showed that intracellular levels of hydrogen peroxide increased in BxPC-3 and Panc-1 cells treated with various concentrations of glucose at 12, 24, $48 \mathrm{~h}$ post-stimulation. Representative data from 3 independent experiments are shown. Values are the means $\pm \mathrm{SD}$ of three independent experiments. $\left({ }^{*} \mathrm{P}<0.05\right.$ compared with $5.5 \mathrm{mM}$ glucose; ${ }^{\#} \mathrm{P}<0.05$ compared with $25 \mathrm{mM}$ glucose).

The Western blot assay was performed following the manufacturer's instructions and was graded positive if the band of interest was present at the expected molecular weight corresponding to each marker protein. All analyses were performed in duplicate.

Statistical analysis. All statistical analyses were performed using the SPSS13.0 software. The results were presented as means \pm SEM of three replicate assays. Differences between the groups were assessed by analysis of variance (ANOVA). Statistical significance was set at $\mathrm{P}<0.05$.

\section{Results}

Hyperglycemia increases the production of ROS in pancreatic cancer cells. The intracellular ROS levels in BxPC-3 and Panc- 1 cells treated with different concentrations of glucose were determined using cell-permeable and redox-sensitive compound DCFDA by flow cytometry. As show in Fig. 1, high glucose (25 and $55 \mathrm{mM}$ ) significantly increased intracellular levels hydrogen peroxide in a concentration-dependent manner after incubation for 12, 24 or $48 \mathrm{~h}$.

Hyperglycemia promotes wound closure. Migration and invasion are two important aspects that lead to the ability of cancer cells to form metastases. In order to further characterize the role of hyperglycemia in aiding metastasis, we investigated the role of high glucose in migration using a classic wound healing assay. Results showed that high glucose caused a significant increase in the migration of BxPC-3 cells after incubation for $24 \mathrm{~h}$ when glucose concentration was changed from 5.5 to $55 \mathrm{mM}$ (Fig. 2A and B). A similar effect emerged in Panc-1 cancer cells (Fig. 2C).

Hyperglycemia augments cell invasion. A critical step of cancer metastasis is invasion of the cancer cell through the basement membrane. In order to confirm whether high glucose can influence the cancer cell invasion ability, we used a transwell invasion assay. We found that increasing glucose levels from 5.5 to $55 \mathrm{mM}$ markedly promoted BxPC-3 cell invasion in a statistically significant and dose-dependent manner after incubation for $24 \mathrm{~h}$ (Fig. 3A and B). This effect was also seen in Panc-1 cancer cells (Fig. 3C).

Expression of UPA and UPAR, responds to high glucose culture in pancreatic cancer cells. UPA and uPA receptor have been implicated in cancer invasion and metastasis. In this study therefore we examined whether high glucose levels could regulate the expression of $\mathrm{UPA}$ and its receptor at the transcriptional level (Fig. 4A and B). We found that the integrated optical density (IOD) of UPA mRNA was up-regulated significantly concomitant with the glucose level in the media from 5.5 to $55 \mathrm{mM}$ at 12,24 and $48 \mathrm{~h}$. The expression of uPAR did not change significantly at the mRNA levels. There was a similar trend in the directionality of the change between the western blot analysis and the results obtained by RT-PCR. In the two pancreatic cancer cell lines, uPA was at relatively weak levels in the $5.5 \mathrm{mM}$ group, whereas the expression of uPA was high in the 25 and $55 \mathrm{mM}$ groups. The expression of uPAR also did not change at the protein levels (Fig. 4C and D).

Hydrogen peroxide promotes wound closure and cell invasion. In order to demonstrate whether the increased cell migration and invasion potential in hyperglycemia was attributed to the production of hydrogen peroxide, we added SOD or SOD with CAT together to the cell media, because SOD could result in an increase in hydrogen peroxide and this increase could be reversed by the hydrogen peroxide-detoxifying enzyme CAT (19). Results showed that SOD caused a significant increase in migration in the wound healing model (Fig. 2) and enhanced the invasion of the two pancreatic cancer cells in 5.5, 25 and $55 \mathrm{mM}$ glucose (Fig. 3). When we added SOD with CAT together into the cell culture, the cell migration and invasion ability decreased significantly, indicating that the migration and invasion mediated by SOD in BxPC-3 and Panc-1 cells was hydrogen peroxidedependent. 



SOD
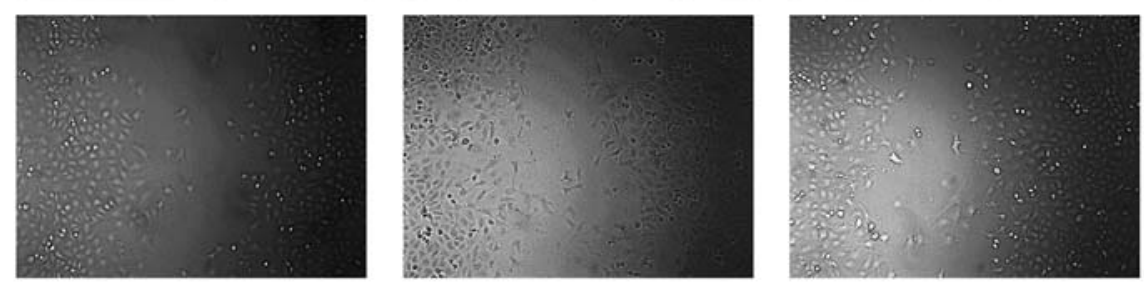

\section{SOD+CAT}

B


Figure 2. Hyperglycemia promotes wound closure and is hydrogen peroxide dependent. The confluent monolayer was wounded with sterile pipette tip and cells were allowed to migrate for $24 \mathrm{~h}$. The migratory ability of BxPC-3 (A and B) and Panc-1 (C) cells was promoted by the increasement of glucose concentration. ( $\mathrm{P}<0.05$ compared with $5.5 \mathrm{mM}$ glucose; ${ }^{\circ} \mathrm{P}<0.05$ compared with $25 \mathrm{mM}$ glucose). Addition of SOD into the media increased the migration of both cell lines. The promigratory effects of SOD were inhibited by CAT. $\left({ }^{*} \mathrm{P}<0.05\right.$ compared with control group; ${ }^{\mathrm{P}}<0.05$ compared with $\mathrm{SOD}$ group).

Involvement of hydrogen peroxide in $u P A$ induction by SOD. First, we arbitrarily chose $24 \mathrm{~h}$ as the cell culture incubation time for further experiments since, the production of hydrogen peroxide increased along with the increase in glucose concentrations at all tested time points of 12,24 or $48 \mathrm{~h}$ as shown above. We then tested the effect of SOD and CAT on the expression of uPA and UPAR. Our results showed that SOD was associated with elevations in uPA mRNA (Fig. 5A and B) and protein production (Fig. 5C and D) in both cell lines and these increases were shown to be a hydrogen peroxidedependent effect, because when we treated cells with SOD and CAT, the expression of uPA was decreased significantly in either mRNA or protein levels. The uPAR expression did not change when we added SOD or SOD with CAT together into the cell media (Fig. 5).

\section{Discussion}

Diabetes mellitus and pancreatic cancer are closely associated. In cancer patients with hyperglycemia or type 2 diabetes, the rate of tumor recurrence, metastatic spread and fatal outcome are higher as compared with the tumor patients without metabolic disease $(20,21)$. In this study, we focused on the effect of hyperglycemia on the invasive and migratory activity of the pancreatic cancer cell lines BxPC-3 and Panc-1.

Our data showed that hyperglycemia can significantly enhance the capacity of the pancreatic cancer cells to migrate and invade the extracellular matrix. However, whether this up-regulation in cellular metastasis behaviour is attributed to the increased energy that is provided by high glucose or some other mechanisms is not known. Therefore, we sub- 


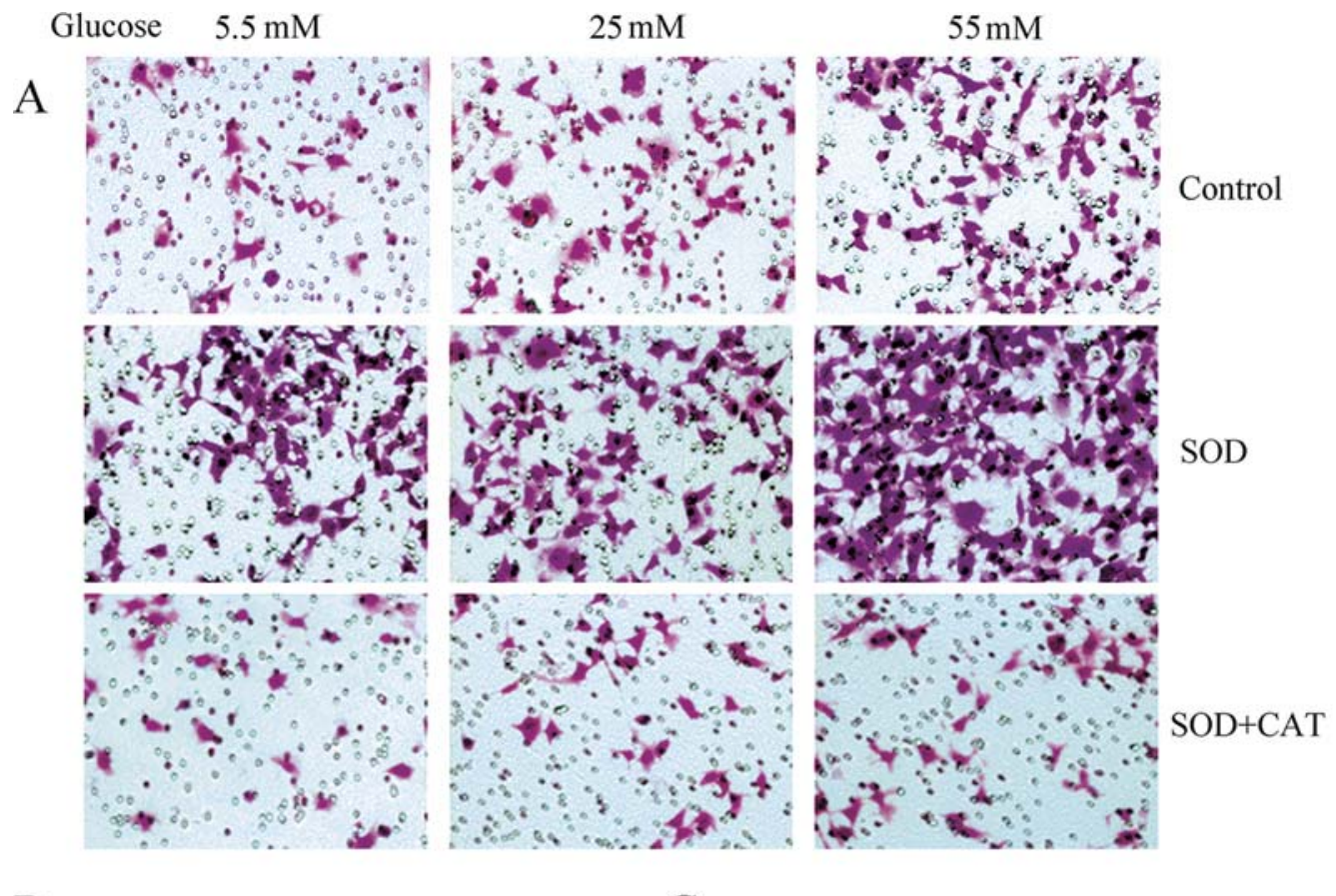

B

$\mathrm{C}$
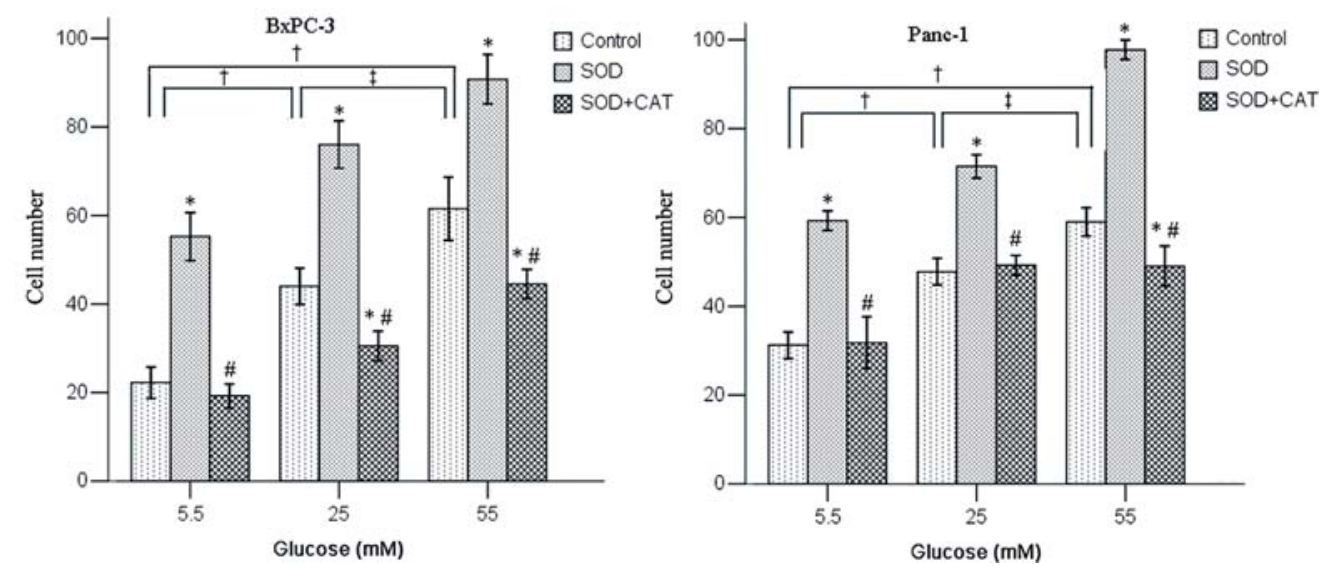

Figure 3. Hyperglycemia promotes invasion of pancreatic cancer cells which is mediated by hydrogen peroxide. Glucose $(5.5-55 \mathrm{mM})$ significantly $(\mathrm{P}<0.05)$ stimulated cell invasion. The images show the bottom side of the filter inserts with stained cells that have migrated through the filter pores. The cell counts are represented in the graph with results of the statistical analysis comparing different treatment groups. ( ${ }^{\dagger} \mathrm{P}<0.05$ compared with $5.5 \mathrm{mM}$ glucose; ${ }^{+} \mathrm{P}<0.05$ compared with $25 \mathrm{mM}$ glucose). SOD significantly $(\mathrm{P}<0.05)$ stimulated cell invasion, while CAT inhibited this SOD-mediated effect. ("P<0.05 compared with control group; ${ }^{\#} \mathrm{P}<0.05$ compared with $\mathrm{SOD}$ group).

sequently tested the production of ROS which had been demonstrated to be linked with cancer metastasis. Then, in order to correlate the cell invasion and migration potential to the increased ROS, we tested the effects of two enzymes, SOD and CAT, which are involved in protection from ROS. With SOD alone, the cell invasiveness increased, whereas the addition of CAT along with SOD to the cell culture resulted in a decrease in the cell invasion and migration ability. This phenomenon suggested that the invasion and migration mediated by SOD in BxPC-3 cells is hydrogen peroxide-dependent. Furthermore, we showed that hyperglycemia can up-regulate the production of uPA in two pancreatic cancer cells; that is, the serine protease was able to proteolytically degrade ECM components and the basement membrane around the primary tumors thus facilitating tumor cell invasion (22).
Tumor metastasis is a multistep process initiated by migration and invasion of cells into the surrounding vasculature. ROS, especially hydrogen peroxide, were proposed to be involved in tumor metastasis $(17,23-25)$. Kozuki et al $(26,27)$ showed that ROS potentiate the invasive activity of the rat ascites hepatoma cell line AH 109A, in a co-culture system with rat mesentery-derived mesothelial cells, and some food factors possessing antioxidative properties were shown to inhibit the invasion of AH 109A cells. Intrinsic antioxidant enzymes are vital to the regulation of oxidative stress within cells. The most important cellular antioxidant enzymes are SOD and CAT. Although they are sometimes classified together, they should be separately considered because their reactions are completely different. SOD accelerates the dismutation rate of superoxide anion into hydrogen peroxide and oxygen, while CAT catabolizes hydrogen 
A



17.5mM Glucose

$\square 25 \mathrm{~mm}$ Glucose

圆 $55 \mathrm{~mm}$ Glucose

B
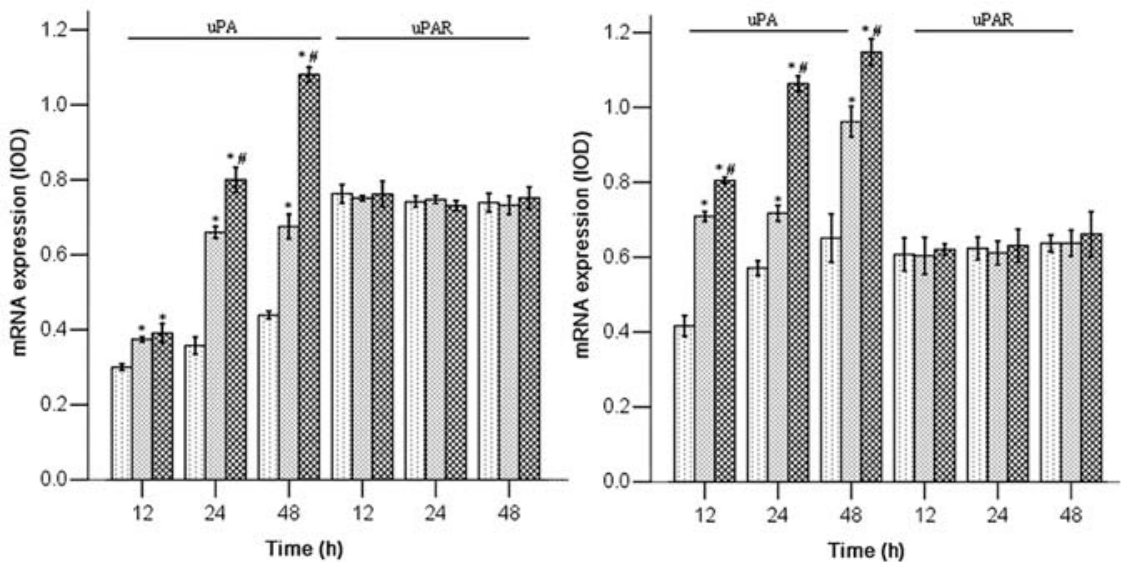

$\mathrm{C}$

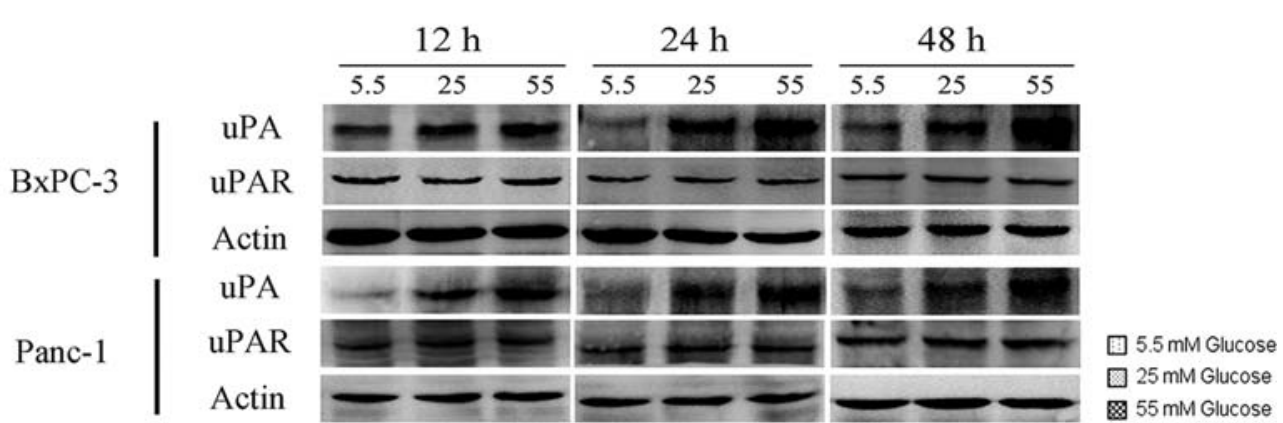

$\mathrm{D}$
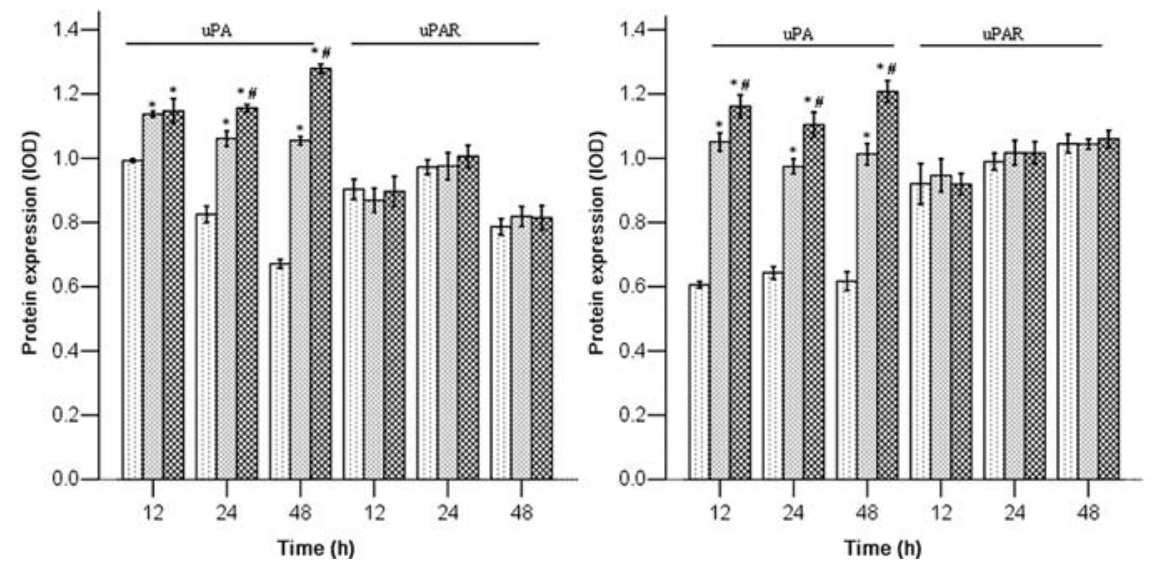

Figure 4. High glucose levels promote the expression of uPA in two kinds of human pancreatic cancer cells, BxPC-3 and Panc-1. uPA mRNA (A and B) and protein $(C$ and $D)$ were gradually up-regulated when the glucose concentrations were increased from 5.5 to $55 \mathrm{mM}$ at culture times of 12,24 and $48 \mathrm{~h}$, whereas the expression of uPAR did not change significantly. $\left({ }^{*} \mathrm{P}<0.05\right.$ as compared with $5.5 \mathrm{mM}$ glucose; ${ }^{\#} \mathrm{P}<0.05$ as compared with $25 \mathrm{mM}$ glucose).

peroxide to water. Hydrogen peroxide and tumor metastasis are intimately related (28). The data showed that elevated levels of SOD are found in the metastatic pancreatic cancer cell line Capan-1 and correlated with an increased frequency of invasion and metastasis of gastric, colorectal cancers $(12,29)$. SOD modulates the invasive properties of cancer cells through hydrogen peroxide production $(25,30)$. Moreover, treatment with CAT derivatives has been shown 


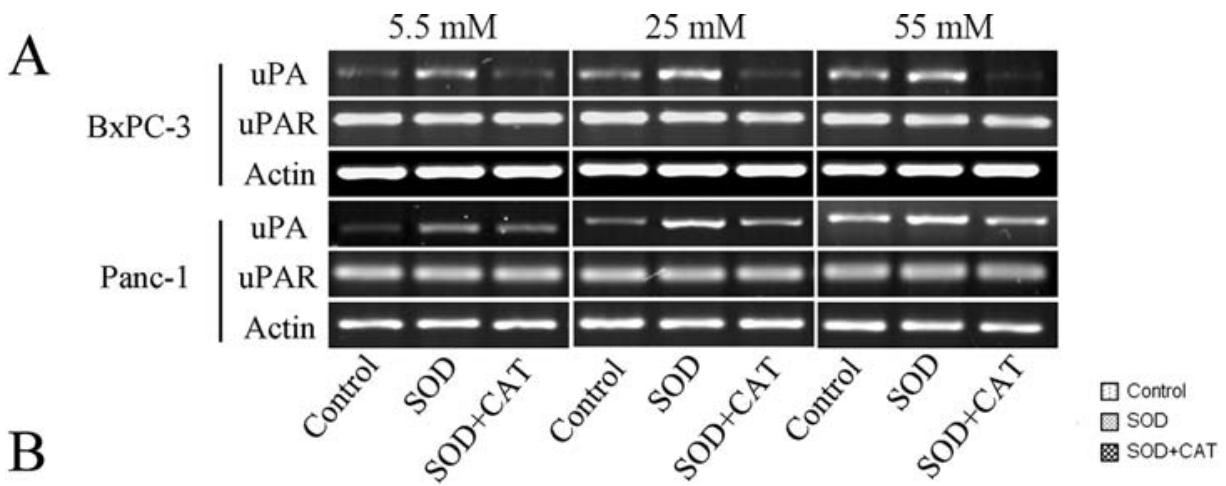

$\mathrm{C}$


$\mathrm{D}$
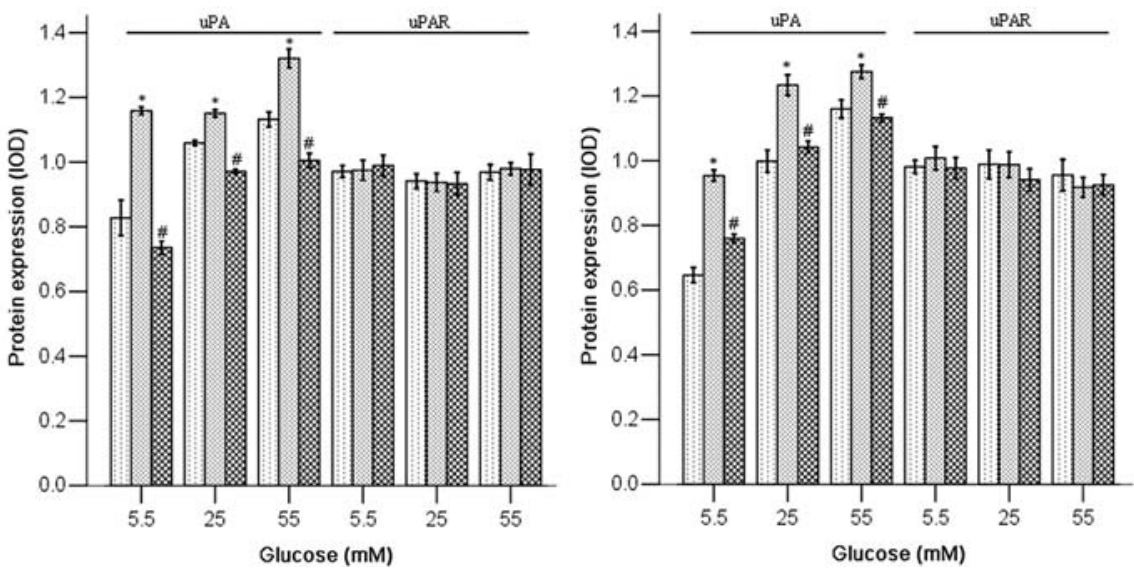

Figure 5. Hydrogen peroxide is able to enhance the expression of uPA. uPA expression was up-regulated by SOD-dependent production of hydrogen peroxide at the mRNA (A and B) or protein (C and D) level in 5.5, 25 and $55 \mathrm{mM}$ glucose, respectively, at 24 h post-stimulation. CAT was shown to inhibit these SOD-mediated increases. The expression of uPAR did not change significantly when the antioxidant enzymes SOD or the combination of SOD and CAT were added during the preincubation. ( ${ }^{*} \mathrm{P}<0.05$ compared with control group; ${ }^{*} \mathrm{P}<0.05$ compared with SOD group).

to significantly reduce the number of metastatic colonies on the surface of the liver, which indicated that the removal of hydrogen peroxide at the interface of tumor cells and liver cells is effective in inhibiting tumor metastasis (13). Furthermore, it has been reported that administration of CAT before the tumor inoculation significantly reduced the number of tumor 
cells in the abdominal cavity which indicate that CAT derivatives inhibit the adhesion of tumor cells (31). In our study, we observed a SOD-dependent production of hydrogen peroxide that led to the increase of the pancreatic cancer cells invasion and migration ability and these effects could be reversed by the hydrogen peroxide-detoxifying enzyme CAT.

Hyperglycemia can cause the production of ROS whose main physiological functions is to regulate the activity of transcription factors. However, oxidative stress has also been shown to be involved in the cell death processes, chromosomal aberrations, or even carcinogenesis. Superoxide anion and hydrogen peroxide are two of the most important ROS molecules. Hyperglycemia can lead to the production of ROS by the mitochondrial electron-transport chain. Increased mitochondrial formation of ROS has been attributed to increased glycolytic production of pyruvate and NADH that in turn leads to an increase of the mitochondrial proton gradient with excess production of $\operatorname{ROS}(7,32)$. There are six major pathways that contribute to production of ROS involving glucose: glyceraldehyde autoxidation, PKC activation, glycation, sorbitol metabolism, hexosamine pathway and oxidative phosphorylation (5). Furthermore, hyperglycemic conditions are responsible for an increase in ROS production that is accompanied by increased fission or decreased fusion to fragment mitochondria. Chronic exposure to high glucose is responsible for a progressive alteration in gene expression, including a decrease in mitochondrial biogenesis. This further impairs oxidative metabolism and increases ROS production, establishing a vicious metabolic cycle that will lead to irreversible tissue damage in diabetes $(33,34)$. Our results confirm that hyperglycemia can increase the production of hydrogen peroxide in pancreatic cancer cell lines BxPC-3 and Panc- 1 .

Cancer cell invasion and metastasis require the concerted action of several proteases that degrade extracellular matrix proteins and basement membranes. Recent reports suggest the uPA system plays a critical role in pancreatic cancer biology. Peroxisome proliferator-activated receptor (PPAR)- $\gamma$ ligands, which are currently in clinical use as antidiabetic drugs, seem to display antitumor activities on pancreatic cancer cell invasion and the plasminogen activator system was assessed (35). Hydrogen peroxide could up-regulate uPA expression in many cancer cell lines and this up-regulation is attenuated by ROS scavenger $(17,18)$. In our study, we found that hyperglycemia dramatically increased the levels of uPA in both BxPC-3 and Panc- 1 cells in different glucose concentrations, and that might be attributed to the increasement of hydrogen proxide, because SOD-dependent production of hydrogen peroxide also enhanced the expression of uPA. We have demonstrated that glucose can enhance the production of hydrogen peroxide and promote the invasion and migration ability of BxPC-3 and Panc-1 cancer cell lines in a concentration-dependent manner. Therefore, our findings may open new pharmacological possibilities for the preventive treatment of pancreatic cancer. Controlling hyperglycemia or even ROS may be a supplemental approach to cancer therapy.

In summary, the results of the present study suggest that hyperglycemia can enhance the invasive and migratory activity of pancreatic cancer cells by mediating the up- regulation of uPA expression via oxidative stress. Managing hyperglycemia or inhibiting the production of ROS may prevent tumor recurrence not only locally, but also at distant sites. Our findings warrant further investigation of this hypothesis.

\section{Acknowledgements}

The authors thank the staffs of the Biology and Genetics Laboratory, Xi'an Jiaotong University for their technical assistance in these studies. This study was supported by grant from National Natural Science Foundation (Grant serial No. 30900705) and Scientific Grant of Xi'an City (2009 No. SF09027).

\section{References}

1. Hezel AF, Kimmelman AC, Stanger BZ, Bardeesy N and Depinho RA: Genetics and biology of pancreatic ductal adenocarcinoma. Genes Dev 20: 1218-1249, 2006.

2. Wray CJ, Ahmad SA, Matthews JB and Lowy AM: Surgery for pancreatic cancer: recent controversies and current practice. Gastroenterology 128: 1626-1641, 2005.

3. Coughlin SS, Calle EE, Teras LR, Petrelli J and Thun MJ: Diabetes mellitus as a predictor of cancer mortality in a large cohort of US adults. Am J Epidemiol 159: 1160-1167, 2004.

4. Stattin P, Bjor O, Ferrari P, Lukanova A, Lenner P, Lindahl B, Hallmans G and Kaaks R: Prospective study of hyperglycemia and cancer risk. Diabetes Care 30: 561-567, 2007.

5. Robertson R, Zhou H, Zhang T and Harmon JS: Chronic oxidative stress as a mechanism for glucose toxicity of the beta cell in type 2 diabetes. Cell Biochem Biophys 48: 139-146, 2007.

6. Inoguchi T, Li P, Umeda F, Yu HY, Kakimoto M, Imamura M, Aoki T, Etoh T, Hashimoto T, Naruse M, Sano H, Utsumi H and Nawata H: High glucose level and free fatty acid stimulate reactive oxygen species production through protein kinase $\mathrm{C}$ dependent activation of $\mathrm{NAD}(\mathrm{P}) \mathrm{H}$ oxidase in cultured vascular cells. Diabetes 49: 1939-1945, 2000.

7. Nishikawa T, Edelstein D, Du XL, Yamagishi S, Matsumura T, Kaneda Y, Yorek MA, Beebe D, Oates PJ, Hammes HP, Giardino I and Brownlee M: Normalizing mitochondrial superoxide production blocks three pathways of hyperglycaemic damage. Nature 404: 787-790, 2000.

8. Sindhu RK, Koo JR, Roberts CK and Vaziri ND: Dysregulation of hepatic superoxide dismutase, catalase and glutathione peroxidase in diabetes: response to insulin and antioxidant therapies. Clin Exp Hypert 26: 43-53, 2004.

9. Abou-Seif MA and Youssef AA: Evaluation of some biochemical changes in diabetic patients. Clin Chim Acta 346: 161-170, 2004.

10. Storz P: Mitochondrial ROS - radical detoxification, mediated by protein kinase D. Trends Cell Biol 17: 13-18, 2007.

11. Ray G, Batra S, Shukla NK, Deo S, Raina V, Ashok S and Husain SA: Lipid peroxidation, free radical production and antioxidant status in breast cancer. Breast Cancer Res Treat 59: 163-170, 2000.

12. Lewis A, Du J, Liu J, Ritchie JM, Oberley LW and Cullen JJ: Metastatic progression of pancreatic cancer: changes in antioxidant enzymes and cell growth. Clin Exp Metastasis 22: 523-532, 2005 .

13. Nishikawa M, Tamada A, Hyoudou K, Umeyama Y, Takahashi Y, Kobayashi Y, Kumai H, Ishida E, Staud F, Yabe Y, Takakura Y, Yamashita F and Hashida M: Inhibition of experimental hepatic metastasis by targeted delivery of catalase in mice. Clin Exp Metastasis 21: 213-221, 2004.

14. Nishikawa M, Tamada A, Kumai H, Yamashita F and Hashida M: Inhibition of experimental pulmonary metastasis by controlling biodistribution of catalase in mice. Int J Cancer 99: 474-479, 2002.

15. Bauer TW, Liu W, Fan F, Camp ER, Yang A, Somcio RJ, Bucana CD, Callahan J, Parry GC, Evans DB, Boyd DD, Mazar AP and Ellis LM: Targeting of urokinase plasminogen activator receptor in human pancreatic carcinoma cells inhibits c-Met- and insulin-like growth factor-I receptor-mediated migration and invasion and orthotopic tumor growth in mice. Cancer Res 65: 7775-7781, 2005. 
16. Schmitt M, Harbeck N, Thomssen C, Wilhelm O, Magdolen V, Reuning U, Ulm K, Hofler H, Janicke F and Graeff $\mathrm{H}$ : Clinical impact of the plasminogen activation system in tumor invasion and metastasis: prognostic relevance and target for therapy. Thromb Haemost 78: 285-296, 1997.

17. Lee KH and Kim JR: Reactive oxygen species regulate the generation of urokinase plasminogen activator in human hepatoma cells via MAPK pathways after treatment with hepatocyte growth factor. Exp Mol Med 41: 180-188, 2009.

18. Lee KH, Kim SW and Kim JR: Reactive oxygen species regulate urokinase plasminogen activator expression and cell invasion via mitogen-activated protein kinase pathways after treatment with hepatocyte growth factor in stomach cancer cells. J Exp Clin Cancer Res 28: 73, 2009.

19. Rodriguez AM, Carrico PM, Mazurkiewicz JE and Melendez JA: Mitochondrial or cytosolic catalase reverses the MnSODdependent inhibition of proliferation by enhancing respiratory chain activity, net ATP production, and decreasing the steady state levels of $\mathrm{H}(2) \mathrm{O}(2)$. Free Radic Biol Med 29: 801-813, 2000.

20. Krechler T, Novotny J, Zeman M, Krska Z, Svestka T, Svab J, Lukas M, Filipova R and Zak A: Pancreatic carcinoma and diabetes mellitus. Cas Lek Cesk 143: 97-100, 2004.

21. Varlotto JM, Recht A, Flickinger JC, Medford-Davis LN Dyer AM and Decamp MM: Factors associated with local and distant recurrence and survival in patients with resected nonsmall cell lung cancer. Cancer 115: 1059-1069, 2009.

22. Muehlenweg B, Sperl S, Magdolen V, Schmitt M and Harbeck N: Interference with the urokinase plasminogen activator system: a promising therapy concept for solid tumours. Expert Opin Biol Ther 1: 683-691, 2001.

23. Nishikawa M, Hashida M and Takakura Y: Catalase delivery for inhibiting ROS-mediated tissue injury and tumor metastasis. Adv Drug Deliv Rev 61: 319-326, 2009.

24. Ushio-Fukai M and Nakamura Y: Reactive oxygen species and angiogenesis: NADPH oxidase as target for cancer therapy. Cancer Lett 266: 37-52, 2008.

25. Connor KM, Hempel N, Nelson KK, Dabiri G, Gamarra A, Belarmino J, van de Water L, Mian BM and Melendez JA Manganese superoxide dismutase enhances the invasive and migratory activity of tumor cells. Cancer Res 67: 10260-10267, 2007.
26. Kozuki Y, Miura Y and Yagasaki K: Inhibitory effects of carotenoids on the invasion of rat ascites hepatoma cells in culture. Cancer Lett 151: 111-115, 2000.

27. Kozuki Y, Miura Y and Yagasaki K: Inhibitory effect of curcumin on the invasion of rat ascites hepatoma cells in vitro and ex vivo. Cytotechnology 35: 57-63, 2001.

28. Kobayashi Y, Nishikawa M, Hyoudou K, Yamashita F and Hashida M: Hydrogen peroxide-mediated nuclear factor kappaB activation in both liver and tumor cells during initial stages of hepatic metastasis. Cancer Sci 99: 1546-1552, 2008.

29. Toh Y, Kuninaka S, Oshiro T, Ikeda Y, Nakashima H, Baba H, Kohnoe S, Okamura T, Mori M and Sugimachi K: Overexpression of manganese superoxide dismutase mRNA may correlate with aggressiveness in gastric and colorectal adenocarcinomas. Int J Oncol 17: 107-112, 2000.

30. Kattan Z, Minig V, Leroy P, Dauca M and Becuwe P: Role of manganese superoxide dismutase on growth and invasive properties of human estrogen-independent breast cancer cells Breast Cancer Res Treat 108: 203-215, 2008.

31. Hyoudou K, Nishikawa M, Kobayashi Y, Kuramoto Y Yamashita $\mathrm{F}$ and Hashida M: Inhibition of adhesion and proliferation of peritoneally disseminated tumor cells by pegylated catalase. Clin Exp Metastasis 23: 269-278, 2006.

32. Brownlee M: Biochemistry and molecular cell biology of diabetic complications. Nature 414: 813-820, 2001.

33. Palmeira CM, Rolo AP, Berthiaume J, Bjork JA and Wallace KB: Hyperglycemia decreases mitochondrial function: the regulatory role of mitochondrial biogenesis. Toxicol Appl Pharmacol 225: 214-220, 2007.

34. Yu T, Robotham JL and Yoon Y: Increased production of reactive oxygen species in hyperglycemic conditions requires dynamic change of mitochondrial morphology. Proc Natl Acad Sci USA 103: 2653-2658, 2006.

35. Sawai H, Liu J, Reber HA, Hines OJ and Eibl G: Activation of peroxisome proliferator-activated receptor-gamma decreases pancreatic cancer cell invasion through modulation of the plasminogen activator system. Mol Cancer Res 4: 159-167, 2006. 